\title{
Desenvolvimento de populações duplo-haplóides de cevada cervejeira associadas à atividade das enzimas (1-3, 1-4)- $\beta$-glucanases
}

\author{
Development of doubled-haploids populations in malting barley associated to activity of enzymes \\ (1-3, 1-4)-ק-glucanases
}

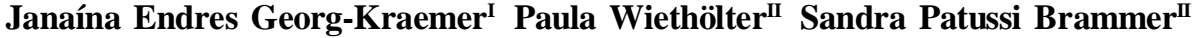 \\ Euclydes Minella ${ }^{\text {II }}$ Edson Jair Iorczeski ${ }^{I I}$ Eduardo Caierão ${ }^{\text {II }}$
}

\section{RESUMO}

Populações duplo-haplóides apresentam especial vantagem para análises genéticas, uma vez que a informação que elas oferecem pode ser maximizada, devido ao fato que todos os locos encontram-se em homozigose. O objetivo deste trabalho foi o desenvolvimento de duas populações duplohaplóides (DHs) de cevada (Hordeum vulgare ssp. vulgare L.) segregantes para a atividade das enzimas (1-3, 1-4)- $\beta$ glucanases, através da técnica de cultura de anteras. Foram realizados dois cruzamentos com cultivares contrastantes para esta característica. As cultivares parentais selecionadas foram 'MN 698' e 'CEV 97047', para o desenvolvimento da população "malte verde" (MV), e 'Embrapa 127'e 'CEV 96025 ' para o desenvolvimento da população "malte seco" (MS). Foram cultivadas 10.734 anteras da população MS e 4.139 anteras da população MV. A população MV produziu $50 \%$ mais plântulas verdes quando comparada à população $M S$, refletindo a importância do genótipo na resposta à cultura de anteras e na regeneração. A maioria das plantas adultas duplo-haplóides foi obtida através da duplicação espontânea in vitro do genoma haplóide, ocorrendo em $66 \%$ das plantas da população MS e $76 \%$ das plantas da população MV. Também foram observadas, em menor frequência, plantas haplóides, triplóides e tetraplóides. Através da técnica de cultura de anteras, foram desenvolvidas 204 linhagens duplo-haplóides, das quais 72 linhagens são da população "malte seco" e 132 linhagens são da população "malte verde". Este material constitui um importante germoplasma para o melhoramento genético da cevada.

Palavras-chave: cultura de anteras, resposta androgenética, Hordeum vulgare ssp. vulgare.

\begin{abstract}
Doubled haploid populations offer special advantages in genetic analyses, since the information they provide may be maximized due to the fact that all loci are homozygous. The aim of this study was to develop two barley (Hordeum vulgare ssp.vulgare L.) doubled-haploid (DHs) populations segregating to $(1-3,1-4)$ - $\beta$-glucanases activity, utilizing the anther culture protocol. Two crosses were performed with contrasting cultivars to (1-3, 1-4)- $\beta$-glucanases activity. Parental cultivars used were 'MN 698' and 'CEV 97047' for the development of 'green malt' population (MV) and Embrapa 127 and 'CEV 96025' for the development of "dry malt" population (MS). For the MS and MV populations, 10,734 and 4,139 anthers were cultured, respectively. MV population produced 50\% more green seedlings as compared to MS population, which reflects the importance of genotype to the culturing of anthers and to regeneration. Most doubled-haploid adult plants were obtained by in vitro spontaneous duplication of the haploid genome, which occurred in 66\% of plants from the MS population and $76 \%$ of plants from the MV population. Haploid, triploid and tetraploid individuals were also observed, though at low frequencies. The anther culture protocol afforded to develop 204 double-haploid lineages, of which 72 were generated by the 'dry malt' population and 132 from the "green malt" population. This material should be considered as important germplasm for barley genetic improvement.
\end{abstract}

Key words: anther culture, androgenetic response, Hordeum vulgare ssp. vulgare.

\section{INTRODUÇÃO}

A cevada (Hordeum vulgare ssp. vulgare L.) é um cereal de inverno e é o quinto grão de maior

'Programa de Pós-graduação em Genética e Toxicologia Aplicada (PPGGTA), Laboratório da Biodiversidade Vegetal, Universidade Luterana do Brasil (ULBRA). Prédio 22, $4^{\circ}$ andar, 92425-900, Canoas, RS, Brasil. E-mail: janaina.kraemer@terra.com.br. Autor para correspondência.

"Embrapa Trigo, Passo Fundo, RS, Brasil. 
importância econômica no mundo. O grão é utilizado na industrialização de bebidas (cerveja e destilados), na composição de farinhas ou flocos para panificação, na produção de medicamentos e na formulação de produtos dietéticos e de sucedâneos de café. A cevada é ainda empregada em alimentação animal como forragem verde e na fabricação de ração (EMBRAPA, 2005). No Brasil, os principais estados produtores de cevada cervejeira são Rio Grande do Sul, Santa Catarina e Paraná. Apesar dos investimentos na produção desta cultura, o Brasil continua sendo um grande importador deste produto. Atualmente, cerca de $30 \%$ dos grãos, utilizados nas maltarias brasileiras, são importados de países do Mercosul e também da Europa (EMBRAPA, 2005).

A produção de linhagens haplóides em altas frequências apresenta grande valor para os produtores e geneticistas, pois representa o meio mais rápido de desenvolver linhagens homozigotas, atuando diretamente no aumento da eficiência da seleção (BOZORGIPOUR \& SNAPE, 1992). A utilização destas linhagens apresenta inúmeras vantagens para o melhoramento vegetal, tais como a eliminação da interação dominância/recessividade, a fixação de determinadas combinações genéticas que eventualmente não seriam observadas, a obtenção de plantas totalmente homozigotas após a diploidização e a redução do tempo necessário para obtenção de linhagens homozigotas para apenas uma geração (ASSMANN, 1996; MORAES-FERNANDES et al., 1999).

Para que a homozigose seja alcançada nos cruzamentos intervarietais, realizados pelo método clássico, são necessárias de sete a nove gerações de autofecundação. Mesmo assim, uma pequena porção de heterozigose residual sempre permanece (MORAESFERNANDES et al., 1999). A grande vantagem da cultura de anteras é o desenvolvimento de linhagens $100 \%$ homozigotas em uma geração. As linhagens duplohaplóides são desenvolvidas a partir dos gametas $\mathrm{F}_{2}$, produzidos pelas plantas $\mathrm{F}_{1}$, chamadas de "plantas doadoras". A haplodiploidização androgenética caracteriza-se pelo cultivo destes gametas, os grãos de pólen, em um meio de cultura específico que estimula o desvio da rota metabólica (HUNTER, 1985), levandoos a se desenvolverem em plantas haplóides. Estas plantas, após a duplicação do genoma, seja de forma espontânea seja induzida, resultam no desenvolvimento de plantas duplo-haplóides. Assim, após uma geração, obtém-se descendentes homozigotos, altamente desejáveis pelos programas de melhoramento.

Na cevada, a cultura de anteras é uma das mais eficientes técnicas para obtenção de haplóides e duplo-haplóides e vários estudos sugerem que alguns fatores genéticos parecem estar envolvidos na capacidade de produção de plantas duplo-haplóide (FAROUGHI-WEHR et al., 1982; LARSEN et al., 1991; WIETHÖLTER et al., 2008). Entretanto, mesmo que a capacidade androgenética esteja associada à presença de genes específicos, o sucesso no desenvolvimento dessas plântulas também depende do estádio fisiológico da planta doadora, do pré-tratamento a frio antes da cultura, do estágio do micrósporo, do meio de cultura, da incubação das anteras e do procedimento de regeneração(OLSEN, 1987; MORAES-FERNANDES et al., 1999).

As cultivares de cevada, selecionadas para fins cervejeiros, devem apresentar tanto características para um bom desempenho a campo, quanto características relacionadas à produção de malte com qualidade. As enzimas (1-3, 1-4)- $\beta$-glucanases (EC 3.2.1.73) são responsáveis por um evento inicial no processo de germinação (malteação) do grão da cevada. Essas enzimas agem na degradação dos ß-glucanos, que são o principal componente das paredes celulares do endosperma amiláceo (WOODWARD \& FINCHER, 1982). A ruptura destas paredes permite que as enzimas diastásicas entrem em contato com os grânulos de amido e atuem na conversão destes em açúcares fermentáveis. A degradação ineficiente das paredes celulares do endosperma prejudica a difusão das enzimas de germinação, a mobilização de reservas do grão e, em decorrência, reduz o extrato do malte. Os $\beta$ glucanos residuais podem gerar problemas na fabricacão de cerveja, tais como: o aumento na viscosidade do mosto e a transparência do produto final. Assim, um dos principais objetivos do programa de melhoramento da cevada é a seleção de cultivares da planta com baixo conteúdo de $\beta$-glucanos e/ou alta atividade das (1-3, 1-4)- $\beta$-glucanases.

O objetivo deste trabalho foi o desenvolvimento de duas populações duplo-haplóides (DHs) de cevada, segregantes quanto à atividade das enzimas (1-3, 1-4)- $\beta$-glucanases, através da técnica de haplodiploidização androgenética.

\section{MATERIAL E MÉTODOS}

A seleção dos genótipos parentais para o desenvolvimento das populações duplo-haplóides (DHs) foi realizada com base na atividade das enzimas $(1-3,1-4)$ - $\beta$-glucanases de 18 variedades de cevada (GEORG-KRAEMER et al., 2004). Foram escolhidas duas cultivares com maior divergência quanto à atividade da enzima na etapa do malte verde (antes da secagem) e outras duas, igualmente divergentes, no 
malte final (malte seco), pois as cultivares que apresentaram maior divergência no malte verde não apresentaram maior divergência para o malte seco. A alta divergência da característica em estudo é essencial para a posterior análise molecular. Foram selecionadas as cultivares 'MN 698' (alta atividade de $\beta$-glucanase) e 'CEV 97047' (baixa atividade de $\beta$-glucanase), para o desenvolvimento da população designada "malte verde" (MV). Para o desenvolvimento da população "malte seco" (MS), foram utilizadas as cultivares 'Embrapa 127' (alta atividade de $\beta$-glucanase) e 'CEV 96025' (baixa atividade de $\beta$-glucanase). Para a obtenção da população MV, a cultivar 'MN 698' foi utilizada como genitor feminino e a 'CEV 97047' como genitor masculino. Para a obtenção da população MS, a cultivar 'Embrapa 127' foi utilizada como genitor feminino e a cultivar 'CEV 96025' como genitor masculino.

A semeadura dos genótipos parentais foi realizada em maio de 2000, na Cia. Brasileira de Bebidas (AmBev), filial Maltaria Navegantes (Encruzilhada doSul, RS). Nos meses de agosto e setembro foram feitos os cruzamentos e em novembro de 2000 as sementes $\mathrm{F}_{1}$ foram colhidas. Para a obtenção das plantas doadoras, em fevereiro de 2001, as sementes $F_{1}$ foram cultivadas na Embrapa Trigo (Passo Fundo, RS), em câmaras de crescimento com condições controladas de fotoperíodo $(14 \mathrm{~h} /$ dia $-10 \mathrm{~h} /$ noite $)$, temperatura $\left(18^{\circ} \mathrm{C}-14^{\circ} \mathrm{C}\right.$, respectivamente) e umidade de $80 \%$. O processo de desenvolvimento das plantas doadoras $\left(\mathrm{F}_{1}\right)$, as etapas da cultura de anteras e a obtenção das sementes das plantas duplo-haplóides foram realizadas na Embrapa Trigo.

As plantas doadoras foram cultivadas em câmaras de crescimento, seguindo as mesmas condições citadas anteriormente. As espigas dessas plantas foram coletadas no período anterior à antese, com grãos de pólen uninucleados, aproximadamente entre 50 e 60 dias após o plantio. A assepsia dos afilhos contendo as espigas foi feita com álcool $70 \%$. Em câmara de fluxo laminar, as espigas foram retiradas dos afilhos e submetidas a um pré-tratamento de 10 dias a $4^{\circ} \mathrm{C}$. Em seguida, as anteras foram coletadas e cultivadas em placas de petri contendo o meio de cultura desenvolvido por HUNTER (1985), com modificações, e mantidas no escuro durante 30 dias a $25^{\circ} \mathrm{C}$. Após, foram armazenadas no claro, na mesma temperatura. As plântulas verdes formadas foram transferidas para tubos de vidro contendo meio de regeneração Batata II (MORAES-FERNANDES \& PICARD, 1983).

As plântulas com bom desenvolvimento apical e radicular foram transferidas para vasos contendo vermiculita como substrato e adubadas com solução nutritiva. A aclimatação das plantas foi feita utilizando-se copos de becker invertidos permitindo que as plantas entrassem gradativamente em contato com o ar. Em torno de 20 dias após a transferência para a vermiculita, foram coletadas pontas de raízes para a determinação do nível de ploidia e para a contagem do número cromossômico, seguindo o método de Squash (GUERRA \& SOUZA, 2002). As raízes das plantas que não tiveram o seu genoma duplicado espontaneamente foram imersas em uma solução de colchicina, em temperatura ambiente, por três horas e, em seguida, transferidas para vasos contendo uma mistura de terra proveniente de dois locais, sendo $40 \%$ de solo e $60 \%$ solo de areia lavada. As plantas que duplicaram o genoma de maneira espontânea não necessitaram nenhum tratamento e foram transferidas diretamente para os vasos com terra. O material foi mantido sob condições controladas até a maturação dos grãos e colheita.

O teste Qui-quadrado foi utilizado, em nível de 5\% de significância, para verificar diferenças entre os parâmetros: AR/AP, PV/AP, PV/AR, PA/AR, PV/TP, DHE/PV, DHE/PAD, PAS/PV, sendo AR: anteras responsivas; AP: anteras plaqueadas (cultivadas); PV: planta verde; PA: planta albina; TP: total de plantas; DHE: duplo-haplóide espontâneo; PAD: planta adulta; PAS: planta adulta com semente.

\section{RESULTADOS E DISCUSSÃO}

Para o desenvolvimento da população malte seco (MS), foram cultivadas 71 plantas doadoras (Tabela 1). Destas plantas, foram coletadas 439 espigas, das quais 13.889 anteras foram plaqueadas. Para o desenvolvimento da população malte verde (MV), foram cultivadas 24 plantas doadoras (Tabela 1), das quais foram coletadas 160 espigas, que permitiram o plaqueamento de 5.708 anteras. Na fase inicial da cultura de anteras, houve a perda de placas, eliminadas do experimento devido à contaminação por fungos. Assim, permaneceram em cultura 10.734 anteras para a população MS e 4.139 anteras para a população MV.

Para o meio de regeneração Batata II, foram transferidas 244 plântulas verdes da população MS e 368 plântulas verdes da população MV (Tabela 1). Nesta etapa, 57 plântulas da população MS foram eliminadas devido à contaminação e/ou problemas de enraizamento, sendo transferidas para a vermiculita apenas 187 plântulas. Para a população MV, 111 plântulas também foram eliminadas devido aos mesmos problemas citados anteriormente, assim, 257 plântulas foram transferidas para a vermiculita.

Algumas das plantas que foram cultivadas na vermiculita apresentaram dificuldades de 
Tabela 1 - Número de plantas resultantes da cultura de anteras das populações malte verde e malte seco conforme o estágio de desenvolvimento da técnica.

\begin{tabular}{|c|c|c|c|}
\hline Análises & Malte seco & Malte verde & Total \\
\hline Plantas doadoras & 71 & 24 & 95 \\
\hline Número inicial de espigas & 439 & 160 & 599 \\
\hline Número inicial de anteras & 13889 & 5708 & 19597 \\
\hline Espigas não contaminadas & 323 & 119 & 442 \\
\hline Anteras cultivadas & 10734 & 4139 & 14873 \\
\hline Anteras responsivas & 2918 & 1474 & 4392 \\
\hline Total de plântulas & 737 & 550 & 675 \\
\hline Plântulas albinas & 493 & 182 & 675 \\
\hline Plântulas verdes & 244 & 368 & 612 \\
\hline Plântulas verdes eliminadas & 57 & 111 & 92 \\
\hline Plântulas transferidas para a vermiculita & 187 & 257 & 444 \\
\hline Plantas transferidas para a terra & 161 & 217 & 378 \\
\hline Plantas adultas & 148 & 186 & 334 \\
\hline \multicolumn{4}{|l|}{ Nível de ploidia: } \\
\hline - Haplóides (n) & 29 & 20 & 49 \\
\hline - Diplóides (2n) & 98 & 141 & 239 \\
\hline - Triplóides (3n) & 1 & 3 & 4 \\
\hline - Tetraplóides (4n) & 7 & 10 & 17 \\
\hline - Ploidia não determinada & 13 & 12 & 25 \\
\hline \multicolumn{4}{|l|}{ Plantas que produziram sementes: } \\
\hline - Haplóides (n) tratadas com colchicina & 3 & 14 & 17 \\
\hline - Diplóides espontâneos (2n) & 69 & 118 & 187 \\
\hline - Triplóides (3n) & 0 & 0 & 0 \\
\hline - Tetraplóides (4n) & 1 & 0 & 1 \\
\hline - Ploidia não determinada & 4 & 4 & 8 \\
\hline - Total de plantas com sementes & 77 & 136 & 213 \\
\hline Total de plantas duplo-haplóides com sementes & 72 & 132 & 204 \\
\hline
\end{tabular}

desenvolvimento. Desta forma, foram transferidas para a terra 161 plantas da população MS e 217 plantas da população MV (Tabela 1). Na terra, 148 plantas da população MS e 186 plantas da população MV desenvolveram-se até a fase adulta.

A contagem dos cromossomos, para verificar o nível de ploidia das plantas, mostrou que $66 \%$ das plantas da população MS e $76 \%$ das plantas da população MV duplicaram o genoma de forma espontânea. Foram observadas, em menor número, haplóides, triplóides e tetraplóides, além de plantas com mais de um nível de ploidia, ou seja, com células diplóides e tetraplóides na mesma planta, impossibilitando, dessa forma, a determinação exata do nível de ploidia (Tabela 1). Estas plantas foram classificadas como "ploidia não determinada" (Tabela 1). Parte do material haplóide que foi submetido ao tratamento com colchicina/DMSO para a duplicação do genoma apresentou dificuldades no desenvolvimento e foi, portanto, eliminado antes da fase adulta. Entre duplo-haplóides espontâneos e induzidos (haplóides tratados com colchicina/DMSO) que produziram sementes, foi desenvolvida a população duplo-haplóide malte seco, constituída por 72 linhas e a população malte verde constituída por 132 linhas.

Apesar das plantas da população MS terem apresentado uma resposta inferior às plantas da população MV durante a indução e regeneração (Tabela 1), as plantas das duas populações apresentaram uma considerável taxa de diploidização espontânea. Isso ocorre porque, na cultura de anteras de cevada, a maioria das plantas é diplóide, sendo comum a presença de uma baixa frequência de plantas haplóides e poliplóides (HUANG \& SUDERLAND, 1982). Este padrão de frequência foi observado tanto para as plantas produzidas na população MS quanto para as plantas produzidas na população MV. HENRY (1998) sugeriu que a duplicação genômica pode ser causada principalmente por dois processos nucleares: a fusão nuclear e a endomitose.

A análise estatística (Tabela 2) não identificou diferenças significativas entre as duas populações no que se refere às relações anteras 
Tabela 2 - Análise estatística (Qui-quadrado) dos resultados obtidos no desenvolvimento das populações duplo-haplóides malte verde e malte seco.

\begin{tabular}{lcccccccc}
\hline & AR/AP & PV/AP & PV/AR & PA/AR & PV/TP & DHE/PV & DHE/PAD & PAS/PV \\
\hline MS & 27,18 & $2,27^{*}$ & $8,36^{*}$ & 16,89 & $33,11^{*}$ & 40,16 & 66,22 & 31,56 \\
MV & 35,61 & $8,89^{*}$ & $24,97^{*}$ & 12,35 & $66,91^{*}$ & 38,31 & 75,80 & 36,96 \\
\hline
\end{tabular}

MS: população malte seco; MV: população malte verde; AR: anteras responsivas; AP: anteras plaqueadas (cultivadas); PV: plântulas verdes; PA: plântulas albinas; TP: total de plântulas; DHE: duplo-haplóides espontâneos; PAD: plantas adultas; PAS: plantas adultas com sementes; * Diferença significativa a $5 \%$.

responsivas/anteras plaqueadas, plântulas albinas/ anteras responsivas, duplo-haplóides espontâneos/ plântulas verdes, duplo-haplóides espontâneos/ plantas adultas e entre plantas adultas com sementes/ plântulas verdes. A produção de duplo-haplóides da população MV foi numericamente superior à população MS (Tabela 1). Uma maior regeneração também foi observada para a população MV quando os dados de produção de plantas verdes/anteras plaqueadas foram comparados aos de plantas verdes/anteras responsivas.

Diferenças significativas (Tabela 2) foram encontradas nas relações de plântulas verdes/anteras plaqueadas, plântulas verdes/anteras responsivas e plântulas verdes/total de plantas, refletindo sempre a superioridade de resposta das plantas da população MV.

Como foi utilizada a mesma técnica de obtenção de plantas doadoras, indução e regeneração de plântulas para a construção das duas populações, pode-se concluir que as diferenças observadas foram devido à capacidade androgenética diferencial destas populações. A população MV foi desenvolvida a partir do cruzamento entre as cultivares 'MN 698' e 'CEV 97047', e a população MS a partir do cruzamento entre as cultivares 'Embrapa 127' e 'CEV 96025'. WIETHÖLTER et al. (2008) observaram que a cultivar 'MN 698' foi estatisticamente superior à cultivar 'Embrapa 127' no que se refere à produção de plântulas verdes. Dessa forma, é possível que as plantas da população MV tenham herdado a capacidade androgenética da cultivar 'MN 698', tendo, por essa razão, obtido maior sucesso no desenvolvimento das plantas duplo-haplóides. Já as plantas da população MS, provavelmente, foram menos responsivas por terem na sua constituição genética a Embrapa 127, uma cultivar com baixa capacidade androgenética.

Estes resultados corroboram com VEILLEUX (1990), que observou que o genótipo é o principal fator atuando nas taxas de respostas à cultura de anteras e regeneração. Em cevada, diversas análises genéticas têm mostrado que a regeneração e a indução estão sob controle de diferentes sistemas poligênicos e são influenciadas por genes com efeitos dominantes, em que um alto número de alelos dominantes refletiria em uma alta resposta à cultura (MARCHETTI et al., 1995; WIETHÖLTER et al., 2008) .

A obtenção de plantas duplo-haplóides de cevada tem sido o objetivo de diversos pesquisadores visando aos mais variados fins, como, por exemplo, para mapeamento genético, no qual a escolha de uma população segregante é decisiva para o sucesso na construção do mapa. Além disso, o uso de populações formadas por plantas homozigotas, como é o caso dos DHs, torna-se obrigatório quando a análise da característica de interesse requer uma grande quantidade de sementes. Este é o caso da análise da atividade das enzimas (1-3,1-4)-ß-glucanases.

\section{CONCLUSÃO}

Através da técnica de haplodiploidização androgenética foram desenvolvidas duas populações duplo-haplóides de cevada segregantes para a atividade das enzimas (1-3, 1-4)-ß3-glucanases, sendo a população "malte seco" constituída por 72 linhagens e a população "malte verde" constituída por 132 linhagens. O desempenho diferencial das plantas das duas populações demonstrou a importância do genótipo na resposta à cultura de anteras e na regeneração. Com a multiplicação deste material, diferentes análises genéticas poderão ser realizadas.

\section{AGRADECIMENTOS}

Os autores agradecem ao Conselho Nacional de Desenvolvimento Científico e Tecnológico $(\mathrm{CNPq})$ e à Cia Brasileira de Bebidas (AmBev), filial Maltaria Navegantes pelo auxílio financeiro recebido. À Embrapa Trigo pelo suporte técnico e uso de seus laboratórios. Em especial, os autores agradecem à Dra. Suzana Smith Cavalli, à Dra. Helga Winge e à Dra. Maria Irene Baggio, pelo grande incentivo ao trabalho realizado.

\section{REFERÊNCIAS}

ASSMANN, E.M. Estudo da resposta androgenética na cultura de anteras in vitro de três cultivares brasileiras 
de cevada, Hordeum vulgare vulgare, Poaceae. 1996. $128 \mathrm{f}$. Dissertação (Mestrado em Genética e Biologia Molecular) Curso de Pós-graduação em Genética e Biologia Molecular, Universidade Federal do Rio Grande do Sul, RS.

BOZORGIPOUR, R.; SNAPE, J.W. The relationship between in vitro performance of haploid embryos and the agronomic performance of the derived haploid lines in barley. Theoretical and Applied Genetics, v.84, p.118-122, 1992. Disponível em: http://www.springerlink.com/content/0040-5752/84/1-2. Acesso em: 19 ago. 2010. doi: 10.1007/BF00223990.

EMBRAPA. Disponível em: <http://www.cnpt.embrapa.br/ culturas/cevada/index.htm>. Acesso em: 15 mar. 2005.

FAROUGHI-WEHR B. et al. On the genetic improvement of androgenetic haploid formation in Hordeum vulgare L. Theoretical and Applied Genetics, v.62, p.233-239, 1982. Disponível em: <https://springerlink3.metapress.com/content/w20411062p8074rj/ resource-secured $/$ ? target $=$ fulltext.pdf $\&$ sid $=1$ hu $12 \mathrm{fjc}$ 1uhg5c55ckl4himw\&sh=www.springerlink.com>. Acesso em: 19 ago. 2010. doi: 10.1007/BF00276246.

GEORG-KRAEMER, J.E. et al. The (1-3,1-4)- $\beta$-Glucanases in Malting Barley: Enzyme Survival and Genetic and Environmental Effects. Journal of the Institute of Brewing, v.110, p.303-308, 2004. Disponível em: <http:// www.scientificsocieties.org/jib/papers/2004/G-2004-1230240.pdf.. Acesso em: 19 ago. 2010.

GUERRA, M.; SOUZA, M.J. de. Como observar cromossomos - um guia de técnicas em citogenética vegetal, animal e humana. Ribeirão Preto: Funpec, 2002. $131 \mathrm{p}$.

HENRY, Y. Origin of microspore derived Dihaploid and Polyhaploid in vitro plants. Plant Tissue Culture and Biotechnology, v.4, p.127-135, 1998.

HUANG, B.; SUNDERLAND, N. Temperature stress pretreatment in barley anther culture. Annals of Botany, v.49, p.77-88, 1982. Disponível em: <http:// aob.oxfordjournals.org/content/vol49/issue1/index.dtl>. Acesso em: 19 ago. 2010.

HUNTER, C.P. The effect of anther orientation on the production of microspore-derived embryoids and plants of Hordeum vulgare cv. Sabarlis. Plant Cell Reports, v.4, p.267268, 1985. Disponível em: <https://springerlink3.metapress.com/ content/g $64330466 \mathrm{xvtu} 4 \mathrm{gt} / \mathrm{res}$ ourcesecured/ ? t a r g e t $=\mathrm{ful} 11 \mathrm{text} \cdot \mathrm{pdf} \& \mathrm{~s}$ i d = n o h f c f v lfg $2 \mathrm{~h}$ 5h55rudcvx $45 \&$ sh=www.springerlink.com>. Acesso em: 19 ago. 2010. doi: 10.1007/BF00269374.
LARSEN, E.T. et al. Nuclear genes affecting percentage of green plants in barley (Hordeum vulgare L.) anther culture. Theoretical and Applied Genetics, v.82, p.417-420, 1991. Disponível em: <https://springerlink3.metapress.com/content/ t $7332680315225 \mathrm{~m} 7 / \mathrm{res}$ ou r c - s e cured/ ? t a r g e t $=$ f u $11 \mathrm{text}$. pdf \& s i d = $1 \mathrm{~h} \mathrm{u} 12 \mathrm{fj} \mathrm{c} 1 \mathrm{uhg}$ 5c55ckl4himw\&sh=www.springerlink.com>. Acesso em: 19 ago. 2010. doi: 10.1007/BF00588593.

MARCHETTI, S. et al. Nuclear and cytoplasmic control of anther culture response in barley (Hordeum vulgare, L.). Czech Journal of Genetics and Plant Breeding, v.49, p.15-20, 1995.

MORAES-FERNANDES, M.I.B.; PICARD, E. Viability of haploid production by anther culture using brazilian wheat genotypes. Revista Brasileira de Genética, v.6, p.261277, 1983.

MORAES-FERNANDES, M.I.B. et al. Haplodiploidização: genética e melhoramento. In: TORRES, A.C. et al. Cultura de tecidos e transformação genética de plantas. Brasília: Embrapa, 1999. Cap.3, p.613-650.

OLSEN, F.L. Induction of microspore embryogenesis in cultured anthers of Hordeum vulgare. The effects of ammonium nitrate, glutamine and asparagine as nitrogen sources. Carlsberg Research Communications, v.52, p.393-404, 1987.

VEILLEUX, R.E. Solanum phureja: anther culture and the induction of haploids in cultivated diploid potato species. In: BAJAJ, Y.P.S. (ed.). Biotechnology in agriculture and forestry. Berlin: Spring-Verlag, 1990. p.530-543.

WIETHÖLTER, P. et al. Genotypic differences in proembryoid development and green plantlets regeneration through androgenesis in barley varieties. Ciência Rural, v.38, p.240242, 2008. Disponível em: <http://www.scielo.br/ s cielo.php? script $=$ sci_art text \& pid=S 0103 84782008000100039\&lng=pt\&nrm=iso>. Acesso em: 19 ago. 2010. doi: 10.1590/S0103-84782008000100039.

WOODWARD, J.R.; FINCHER, G.B. Substrate specificities and kinetic properties of two $(1 \rightarrow 3)(1 \rightarrow 4)-\beta$-D-glucan endo-hydrolases from germinating barley (Hordeum vulgare). Carbohydrate Research, v.106, p.111-122, 1982. Disponível em: <http:// www.sciencedirect.com/science?_ob=ArticleURL\&_udi=B6TFF42 H85XR7W\&_user $=687304 \&$ \& coverDate $=08 \% 2$ F0 $1 \% 2$ $\mathrm{F} 1982 \&$ \&doc $=10 \&$ \& fmt $=$ high \&_orig $=$ browse\&_srch $=$ docinfo $(\%$ 23 toc \%235225\%231982\%23998939998\%23234144 $\% 23$ FLP \% 23 display $\% 23$ Volume) \&_cdi=5225\& _ sort $=$ d \&_d o c a n c hor $=\& \&_{\text {_ }} \mathrm{ct}=19 \& \&_{-}$a c c t $=$ $\bar{C} 000037798 \&$ \&_version $=1 \&_{\text {_ u r } 1 \text { Version }}=0 \&$ \&_us erid $=687304 \& \mathrm{md} 5=$ ea5be54becdaf $77479 \mathrm{fd} 2490 \mathrm{daae} 2697>$. Acesso em: 19 ago. 2010. doi: 10.1016/S0008-6215(00)80737-5. 